\title{
Reassessment of Crystal Growth Theory of Graphite in Cast Iron
}

\author{
Doru M. Stefanescu ${ }^{1, a}$, Gorka Alonso ${ }^{2, b}$, Pello Larrañaga ${ }^{2, c}$, \\ Esther De la Fuente ${ }^{3, d}$, Ramón Suarez ${ }^{2,3, e}$
}

${ }^{1}$ Ohio State Univ., Columbus, Ohio and Univ. of Alabama, Tuscaloosa, Alabama, USA

${ }^{2}$ IK4-Azterlan, Durango (Bizkaia), Spain

${ }^{3}$ Veigalan Estudio 2010 S.L.U., Durango (Bizkaia), Spain

a stefanescu.1@osu.edu, bgalonso@azterlan.es, " plarranaga@azterlan.es,

'edelafuente@azterlan.es, ersuarez@azterlan.es

Keywords: cast iron, graphite morphology, foliated dendrites, graphite growth

\begin{abstract}
The problem of graphite crystallization and growth in cast iron has recently received increased attention. As most of the literature data describe analysis of room temperature graphite, there is a legitimate concern that the crystallization of graphite is obscured by subsequent recrystallization and growth in solid state. To avoid confusion in the interpretation of room temperature graphite morphology, the authors used Field Emission Gun Scanning Electron Microscopy on deep-etched interrupted solidification (quenched) specimens to reveal the morphology of graphite at the very beginning of solidification, when the graphite is in contact with the liquid. Information from related phenomena, such as crystallization of hexagonal structure snowflakes and metamorphic graphite, as well as of diamond cubic structure silicon crystals in aluminum alloys is incorporated in the analysis. Research discussing graphite produced through gas-solid and solid-solid transformations is also examined.

Because the faceted growth of graphite is the result of diffusion-limited crystal growth in the presence of anisotropic surface energy and anisotropic attachment kinetics, a variety of solidification morphologies are found. The basic building blocks of the graphite aggregates are hexagonal faceted graphite platelets generated through the growth of graphene layers. As solidification advances, the platelets thicken through 2-D nucleation or spiral dislocation growth. Depending on bulk composition, local supersaturation and undercooling, the platelets aggregate through a variety of mechanisms including foliated/tiled-roof crystals and dendrites, curvedcircumferential, cone-helix, helical (macro-spiral), and polyhedral columnar or conical (pyramidal) sectors growth.
\end{abstract}

\section{Introduction}

There are several allotropes of carbon based on a hexagonal lattice: 0-D fullerene, 1-D carbon nanotube, 2-D graphene, and 3-D graphite [1]. Graphite has a layer-structured of graphene layers in which the carbon atoms are arranged in a honeycomb lattice. The strong sigma-bonds in layers and weak Pi-bonds between layers produce the faceted morphology and high anisotropic behavior of graphite. Typically, graphite grows faster along the tightly-bond $a$-axis directions [1010], rather than in the loosely-bond $c$-axis direction [0001]. This explains the graphite flakes in natural graphite and in gray iron. Yet, in $\mathrm{Ni}-\mathrm{C}, \mathrm{Co}-\mathrm{C}$, and $\mathrm{Fe}-\mathrm{C}$ alloys, spheroidal graphite can be produced, where the graphite aggregate appears to extend in the $c$-direction rather than the $a$-direction.

Understanding the mechanisms involved in the genesis of the graphite morphology in cast iron is made difficult by the complexity of graphite crystallization. The interplay between the chemistry of the iron melt, and the transitory nature of nucleation and local segregation, produce a large variety of graphite shapes, including the "standard" shapes: lamellar/flake (LG), compacted/vermicular (CG), spheroidal/nodular (SG), and temper graphite (in malleable iron). In addition, "degenerated" morphology, such as spiky, exploded, or chunky graphite, can result from incorrect melt treatment or unfavorable cooling conditions. It is useful to succinctly explore not only crystallization of graphite through liquid-solid transformation, but also that through gas-solid and solid-solid 
transformation, as well as phase crystallization in some analogous faceted systems and in metamorphic graphite.

\section{Analogous Systems}

The term "analogous systems" is used to describe systems that exhibit crystal shapes like that of graphite in cast iron, such as snow crystals, $\mathrm{Si}$ in Al-based alloys, and graphite in Ni-C or Co-C alloys.

Natural ice (snow crystals) has a hexagonal crystalline structure composed of water molecules located on the apex of hexagons. Nakaya [2] established that the morphological stability of ice crystals is controlled by supersaturation, temperature, and crystal size. Higher supersaturation (humidity) favors complex dendritic shapes, while lower supersaturation produces plates and prisms with a hexagonal habit. Hexagonal polyhedral crystals, with a substructure of pyramidal sectors, develop in the $c$-direction, with platelets oriented perpendicular to the radius. Polyhedral-todendritic or dendritic-to-polyhedral growth transitions may occur, depending on local conditions.

Silicon crystallizes with a face-centered diamond cubic structure. Analogies between the solidification of Al-Si alloys and cast iron have been discussed [3,4,5,6]. Eutectic Si grows as faceted fibers, and may produce dendrites or spheroids. Primary Si crystals with nearly ideal octahedral shape have been also observed in cast hypereutectic Al-Si alloys [7]. Eutectic Si in nonmodified sand-cast $\mathrm{A} 19 \mathrm{Si} 3 \mathrm{Cu}$ alloy solidifies as platelets that appear to be foliated dendrites (note growth of protuberances joining plates in Fig. 1) [8]. Foliated crystals and dendrites, which are assemblies of thin plates separated by solvent impurity layers, first described by Saratovkin [9], and then advocated by Roviglione and Hermida [10] and by the authors of this paper [11,12] for graphite, were also observed in an $\mathrm{Al}-\mathrm{Ti}$ alloy, where the faceted $\mathrm{Al}_{3} \mathrm{Ti}$ phase developed into "tiled-roof" structure [13].

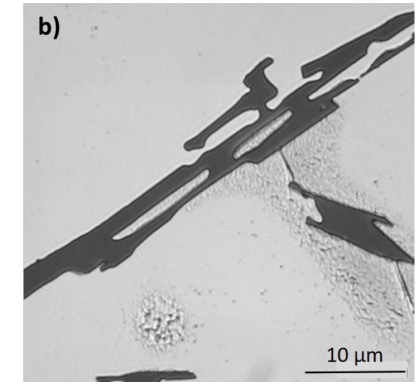

Fig. 1. Optical image of eutectic Si platelets; foliated dendrites [8]

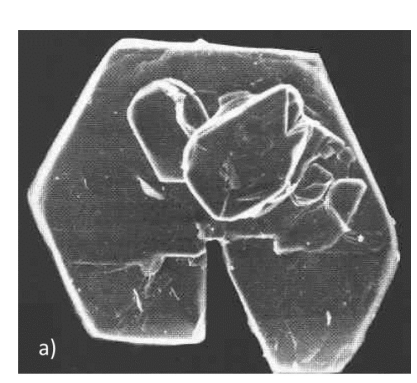

Fig. 2. Helical growth of metamorphic graphite; note hexagonal hole. Crystal sizes range from 0.2 to $0.5 \mathrm{~mm}$ across [14]

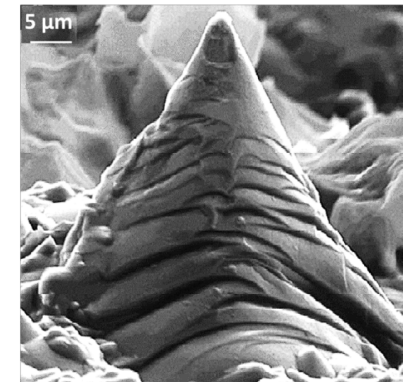

Fig. 3. Graphite cone in metamorphic graphite

[18]

Metamorphic graphite is natural graphite formed through transformation by heat, pressure, or other natural actions. Most of the graphite crystals deposited from a carbon-rich fluid, show layergrowth in the [0001] direction [14]. In some crystals, steps originate at the center of the polyhedron faces (Fig. 2-a). The rotation introduces crystal defects known as disclinations [15,16,17]. It was suggested [14] that early-stage helical (macro-spiral) growth because of a negative wedge disclination (Fig. 11-c,d) is conducive to the bending of the graphene sheets and to polygonization into separate blocks (Fig. 2-b). Polyhedral growth and the deviation of parallelism of the crystallite blocks, may result in columnar or nearly spherical morphologies. Jaszczaka et al. [18] reported on the finding of cones formed from a metamorphic fluid on the surfaces of mm-size polycrystalline SG. Steps on the cone surfaces (Fig. 3) are an indication of a layer-growth mechanism. The ridges found on some cones suggests growth through the cone-helix model.

Graphite morphology in nickel-carbon alloys is similar to that in $\mathrm{Fe}-\mathrm{C}$ alloys. Double and Hellawell [15] concluded that the graphite plates in a $\mathrm{Ni}-2.1 \% \mathrm{C}$ eutectic alloy are composed of layers (platelets) of fault free crystal some $10 \mu \mathrm{m}$ thick. Lux et al. [19] found dendritic branching of primary graphite crystals in Ni-C alloys. 
Amini and Abbaschian [20] demonstrated that, upon cooling of hypereutectic Ni-3\% C alloys, primary graphite can grow either with flake or spherical morphology, depending on solidification rate and supersaturation. They argued that morphological transition is the result of changing from growth of the ledges produced by 2-D nucleation to carbon diffusion-limited growth. Fig. 4-a suggests that the structure is the result of bending of the graphite platelets, as originally postulated by Sadocha and Gruzlesky [21] under the terminology "circumferential growth" or "curved-crystal growth". Columnar growth is seen in the Fig. 4-b.
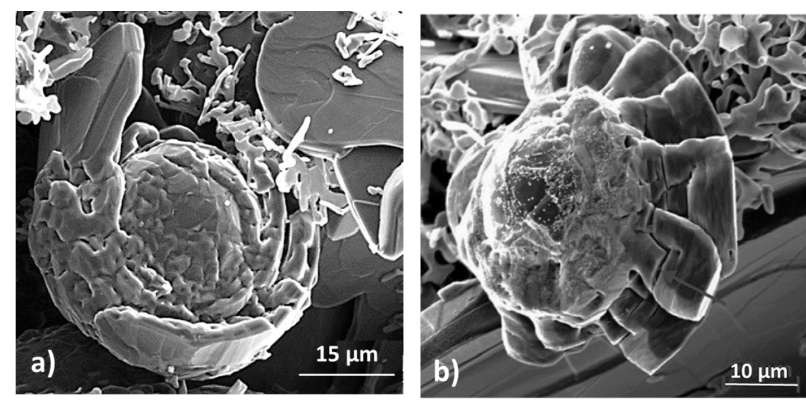

Fig. 4. SEM images of graphite growing in Ni-3\% C melts: a) curved-circumferential and lamellar growth; b) columnar growth [20]
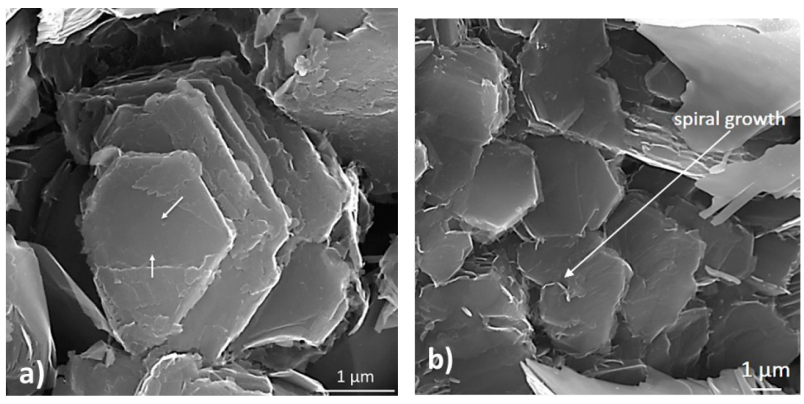

Fig. 5. Thickening of graphite platelets in compacted graphite iron: a) growth front of new graphene layers [11]; b) spiral growth [12]

\section{Graphite Produced through Solid-Solid and Gas-Solid Transformations}

In Fe-C alloys, graphite may also precipitate through a solid-solid transformation (e.g. annealing of white iron and heat treatment of carbon steel). The structure of the spheroidal nodules found in quenched and annealed $0.38 \%$ carbon steel by He et al. [22] suggested radial growth of inverse conical sectors, similar to the Double/Hellawell [15] cone-helix mechanism. Yet, the He et al. mechanism assumes spiral-dislocation growth in the $c$-direction (Fig. 11-g).

Li et al. [23] study of SG obtained by heat treatment of medium carbon steel, also concluded that the graphite aggregate is built of radial sectors, and that the building blocks of the sectors are graphite platelets, $10-30 \mathrm{~nm}$ thick and hundreds of $\mathrm{nm}$ long, growing nearly parallel, with misorientation of up to $20^{\circ}$. They argue that the lengthening in $a$-direction is constrained by multiple site nucleation around the nucleus. The basal planes extend in the $c$-direction by 2-D nucleation and grow into radial cones. The authors further argue that the layer-by-layer thickening by 2-D nucleation on basal plane supports the He et al. modified version of the cone-helix model. Examination of pyrolytic graphite demonstrated that graphite spheres obtained through gas-solid transformation have similar structure of radial sectors in the cross section as the SG in steel (solidsolid transformation), or the SG in ductile iron (liquid-solid transformation).

\section{Graphite Produced through Liquid-Solid Transformation}

SEM analysis of deep-etched interrupted solidification samples revealed that the basic building blocks of the graphite aggregates are hexagonal faceted graphite platelets with nanometer height in the $c$-direction and micrometer width in the $a$-direction $[11,12]$. Thickening of the platelets occurs through growth of additional graphene layers nucleated at the ledges of the platelets (Fig. 5-a), or through spiral-dislocation growth (Fig. 5-b).

In the initial stage, lamellar graphite grows from the liquid as crystalline hexagonal parallel platelets, with growth morphology consistent with that of foliated dendrites (Fig. 6-b). In later stages, the foliated dendrites produce layered faceted crystals with a tiled-roof configuration (Fig. 6a). This confirm early TEM work on lamellar graphite [24]. More recent TEM work by Hara et al. [25] also concluded that the internal structure of flake graphite consisted of thin layers of graphite platelets arranged in a "mosaic-like" structure, which is the tiled-roof configuration.

SEM analysis of interrupted solidification experiments of low-Mg iron revealed a gradual change of platelets stacking from the tiled-roof $a$-direction, to the $c$-direction [11] to produce 
compacted or chunky graphite with dendritic configuration (Fig. 7). A clear dendritic growth pattern was found in an Sb-alloyed CG iron (Fig. 8-a). The foliated graphite platelets stacked predominantly along the $c$-axis and clustered as polyhedral blocks (Fig. 8-b) oriented at various angles with respect to one another.

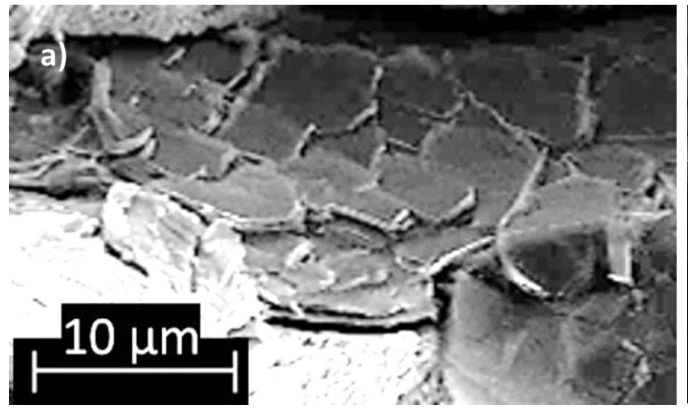

Fig. 6. SEM images of graphite lamellae: a) fatigue-fractured area in LG iron; compliments of W.L. Guesser and the Tupy/SE-NAI project; b) dendritic stacking of foliated platelets growing on $\mathrm{Fe}_{3} \mathrm{C}$ [11]

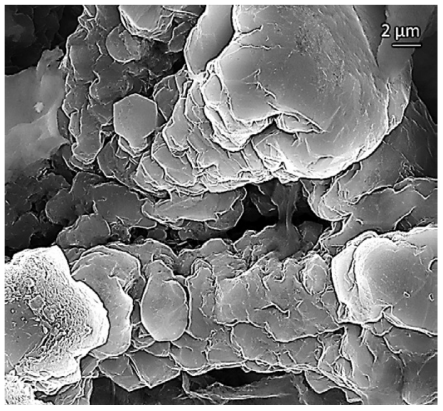

Fig. 7. Stacking of graphite plates along the $c$-direction to produce chunky graphite [11]

Dendritic graphite growing on an imperfect graphite spheroid found in a $\mathrm{Ni}-\mathrm{C}$ melt was reported by Minkoff and Einbinder [26], who further argued that every branch of the dendrite was an independent columnar crystal grown from its own nucleus situated along the principal trunk of the dendrite. Hamasumi [27] identified graphite dendrites made of sectors extending in the $c$-direction in graphite spheroids in a large SG iron casting (Fig. 8-c).
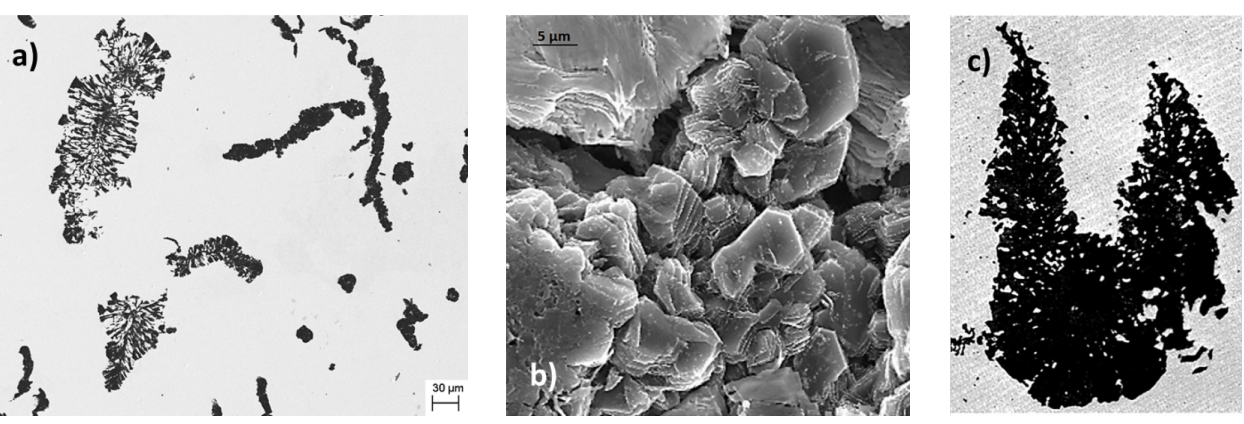

Fig. 8. Dendritic graphite: a) graphite dendrites in $0.01 \% \mathrm{Sb}$ CG iron [36]; b) SEM image of (a) [36]; c) graphite spheroid

with dendritic outgrowth; $\mathrm{x} 250$ [27]

The room temperature spheroidal graphite is the product of three processes: i) nucleation and growth in the liquid; ii) growth during the eutectic transformation; iii) growth during cooling to room temperature as the solubility of carbon in austenite decreases. In the early work of Lalich and Hitchings [28], two stages of graphite development can be distinguished upon early interrupted solidification: i) growth of graphite around the heterogeneous nucleus, and ii) further growth of graphite in contact with the liquid (Fig. 9-a). The graphite appears to grow as curved plates around the spherical nucleus. The concentric orientation of the platelets in the $2^{\text {nd }}$ stage, also suggest curved growth. In a sample obtained immediately after the end of solidification (Fig. 9-b), two stages are still observed, with columnar sectors in stage II. At room temperature, the graphite structure exhibits a herring-bone dendritic orientation (Fig. 9-c), or a concentric orientation (Fig. 9-d).
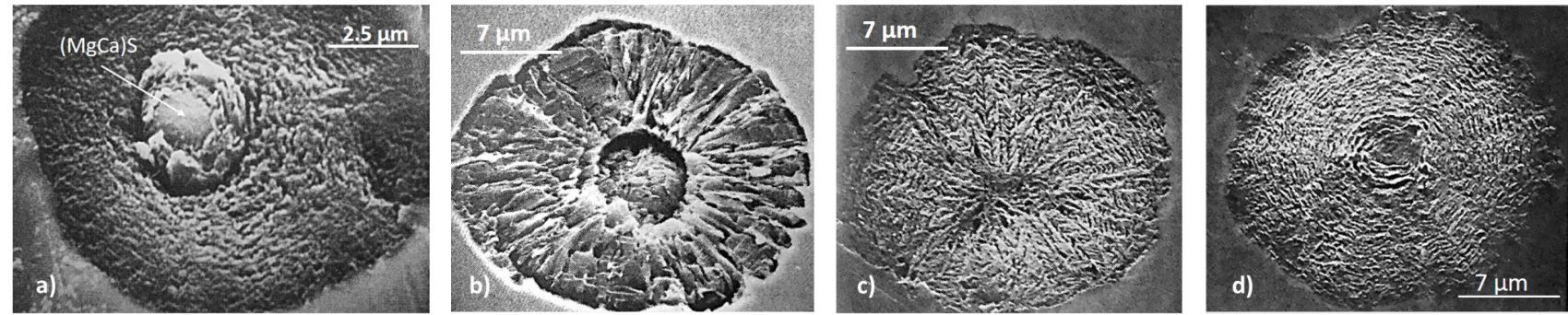

Fig. 9. Effect of the time at which the sample was obtained during solidification and cooling to room temperature on the microstructure of SG [28]; a) quenched from $1288^{\circ} \mathrm{C}$; b) quenched at the end of the eutectic reaction; c) as-cast, herring-bone dendritic appearance; d) as-cast, concentric orientation 
After austenite encapsulation of the spheroid during the eutectic reaction, graphite growth continues through solid diffusion of carbon through the austenite. TEM images of a fractured graphite spheroid obtained by Purdy and Audier [29] demonstrated the layer growth of graphite platelets through the crystallization of amorphous carbon diffused through the austenite.

A TEM study by Miao et al. [30] concluded that the structure of graphite spheroids consists of rhombohedral graphite platelets with their [001] directions nearly parallel to the radius of the spheroid growing through the cone-helix mechanism. Randomly orientated graphite, with a hexagonal rather than rhombohedral structure, is located in the interplatelet areas. Hara et al. [25] concluded that SG has a three-fold internal structure, with and amorphous central region, annular rings of a layered intermediate region, and a mosaic-like (tiled-roof) outer region made of large polygonal crystalline platelets. Recent TEM work by Theuwissen et al. [31], argues that both flake and spheroidal graphite consist of blocks stacked upon each other that grow mainly by a 2D nucleation mechanism.

\section{Experimental Work}

The focus of the experimental work was directed to documenting the morphology of spheroidal and chunky graphite in the early stages of solidification and at room-temperature.

Interrupted solidification experiments of CG and SG iron. The interrupted solidification experimental technique (see ref. [11,12] for details) was used to produce graphite aggregates grown predominantly in the liquid, avoiding morphological changes caused by solid diffusion growth. Cast iron melts of industrial purity $(3.3-3.8 \% \mathrm{C}, 1.9-2.1 \% \mathrm{Si}, 0.02-0.044 \% \mathrm{Mg}$ ) were produced. Their chemical analysis was designed such as to obtain $20 \%$ to higher than $80 \% \mathrm{SG}$. Thermal analysis (TA) cups were poured, and then immediately quenched in water to interrupt the solidification process. The investigation focused on graphite aggregates visible after deep etching under the metallographic polishing surface (whole aggregates), and aggregates sectioned by the polishing plane (sectioned aggregates). A good example of foliated dendrites growth was found in the $0.02 \%$ $\mathrm{Mg}$ iron, where during early solidification, polygonal flat platelets grow in a tiled-roof configuration (Fig. 10-a). Other well-formed graphite spheroids show a coarse surface with hexagonal platelets and polyhedral blocks with numerous growth imperfections (Fig. 10-b).
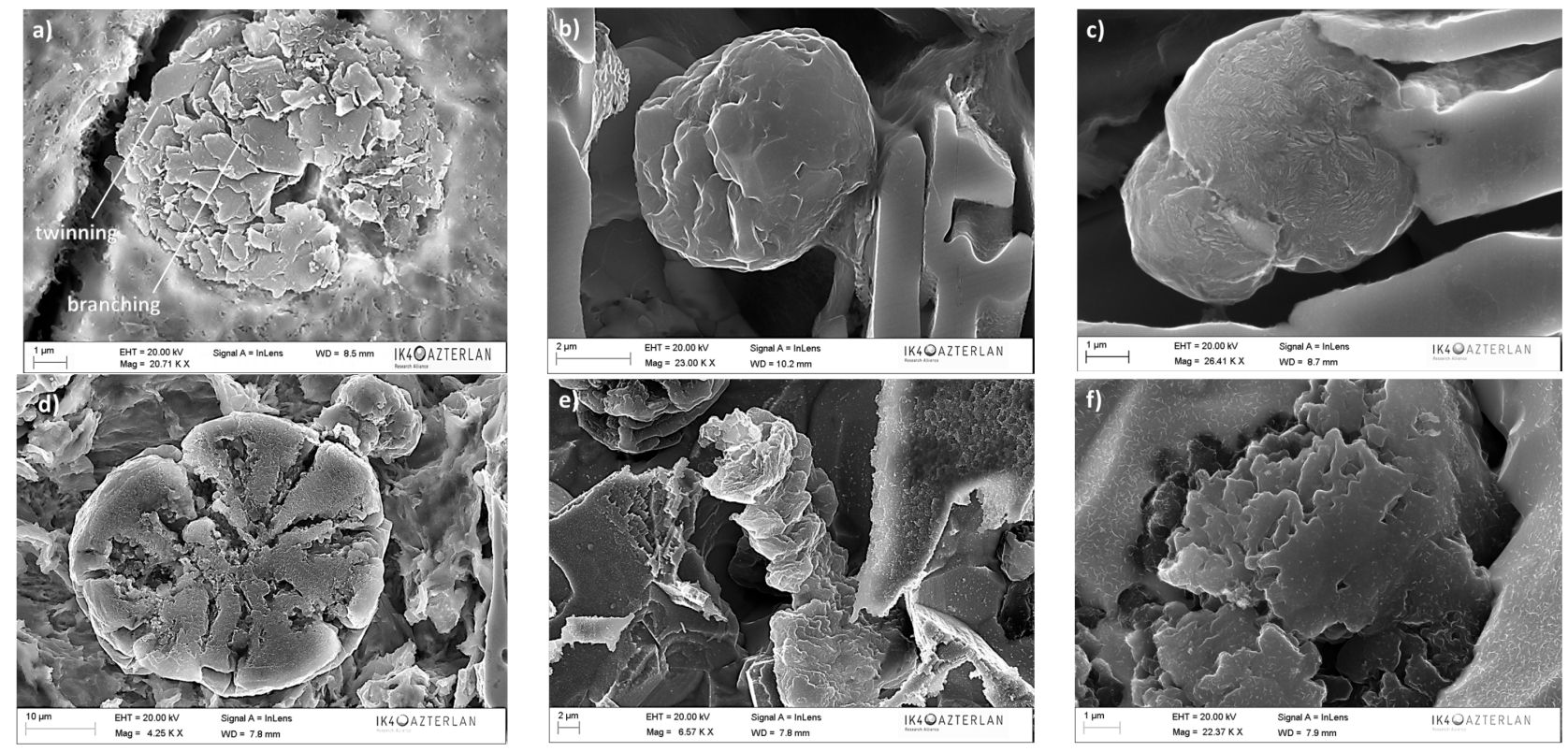

Fig. 10. SEM image of graphite aggregates: a) whole graphite, foliated dendrites; b) whole graphite, polyhedral blocks; c) sectioned graphite, conical sectors with herring-bone platelets; d) section of an imperfect spheroid with conical sectors composed of platelets in tiled-roof pattern; e) helical growth in chunky graphite; f) foliated dendrites in chunky graphite 
Some sectioned well-formed graphite spheroids exhibited platelets with a concentric distribution around a spherical nucleus, while others form columns of dendritic appearance, because the [0001] axis of the platelets is at an angle with the growth direction of the columns (Fig. 10-c). A diametric section through an imperfect nodule revealed that it was built of individual inverse conical columns, growing from a common center (Fig. 10-d). The conical columns are assemblies of graphite platelets distributed in a tiled-roof configuration.

Room-temperature structure of chunky graphite. SEM images of chunky graphite from an industrial room-temperature sample (composition mass \%: $3.72 \mathrm{C}, 2.09 \mathrm{Si}, 0.12 \mathrm{Mn}, 0.012 \mathrm{~S}$, $0.052 \mathrm{Mg}, 0.0006 \mathrm{Ce}, 0.0056 \mathrm{La}, 0.0021 \mathrm{Sb}, 0.005 \mathrm{Sn})$ in Fig. 10-e,f exhibit helical growth and foliated dendrites.

\section{Discussion}

The preceding analysis of the growth of hexagonal and diamond cubic faceted crystals has revealed that polyhedral, pyramidal sectors, stem-dendritic, or foliated-dendritic configurations may be produced. Increased undercooling and supersaturation favors transition from polyhedral to dendritic growth. In the case of ice, further increase in undercooling reverts growth to polyhedral.

At the nanoscale, relevant to the growth of the graphite platelets, atomically rough interfaces (non-faceted crystals such as iron) grow normal to the solid/liquid interface (continuous growth). Atomically smooth interfaces (faceted crystals such as graphite or silicon) grow parallel to the interface through layer-growth (lateral growth). Both 2-D nucleation [20,31] and spiral-dislocation $[14,12]$ layer-growth were documented in graphite crystals. Layer-growth also occurs in solid state through crystallization of amorphous carbon diffused from the melt [29].

At the microscale, pertinent to the aggregation of the platelets, hexagonal crystals can have a polyhedral (needle, plate, column) or dendritic (stem or foliated) configuration. The most significant microscale growth mechanisms are summarized in Fig. 11. There is significant literature evidence that the spherical form of the graphite during early solidification is the result of curvedcircumferential growth (Fig. 4-a, Fig. 9-a,b), fact confirmed through experiments reported in this work. Yet, as the outermost platelets in Fig. 4-a are separated from the platelets under them, the curved platelets do not seem to be the result of layer-growth. They may well be the result of curvedfoliated crystal growth.
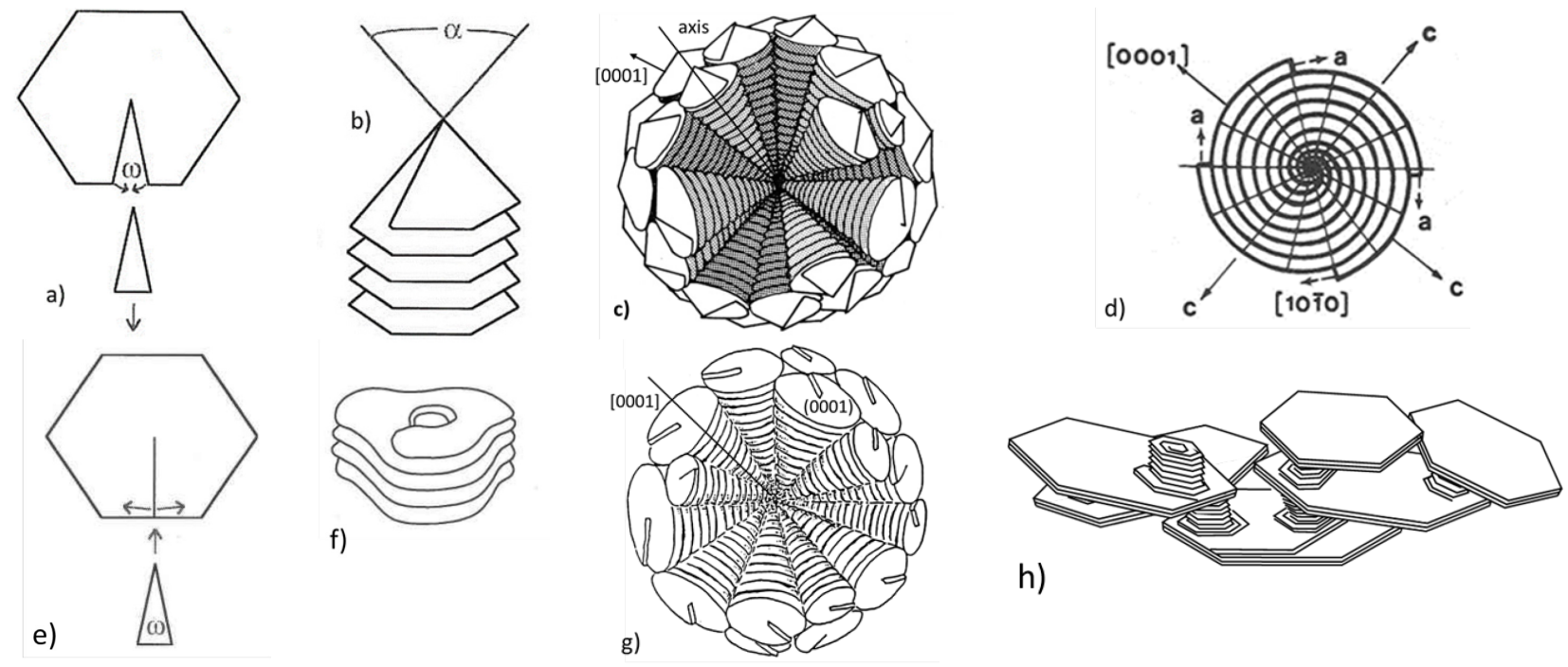

Fig. 11. Schematic representation of various growth mechanisms of graphite aggregates: a) positive wedge disclination [14]; b) cone-helix growth; c) cone-helix growth of conical sectors [15]; d) curvedcircumferential growth [21]; e) negative wedge disclination [14]; f) wavy helical (macro-spiral) growth [14]; g) spiral dislocation growth of conical sectors [22]; h) foliated crystal/dendrite growth [12]

Positive wedge disclination (Fig. 11-a,b) with a screw dislocation component has been advance to explain the cone-helix growth of graphite crystals, such as graphite cones, and whiskers [16,17]. 
One of the objections to the cone-helix model is that the $\{001\}$ planes of graphite which are rotated around the cone symmetry axis, are at an angle with respect to the axis of the cone. Yet, TEM data, e.g. [22,31], show that the [0001] direction of graphite planes is parallel to the symmetry axis of the cone in the graphite spheroid. A possible explanation is the angle at which the cone-helix is sectioned by the metallographic plane [15]. A modified spiral-dislocation growth mechanism (Fig. 11-g) was suggested by Miao et al. [30] as an alternative mechanism.

Helical growth resulting from negative wedge disclination (Fig. 11-e,f) can produce thick plates that spiral upward during growth, as exemplified for metamorphic graphite in Fig. 2-a,b. The growth product is graphite polyhedral blocks. For cast iron, the helical growth illustrated in Fig. 12-a [19], was attributed to a growth inhibitor. It has been suggested to operate in the growth of chunky graphite [32], and further confirmed in this work (Fig. 10-e). Helical growth can produce hollow prisms, as found in metamorphic graphite (Fig. 2-b), but also in ice crystals and graphite spheroids in iron (Fig. 12-b). Dendritic growth of degenerated graphite documented in Fig. 8-c, appears to be a combination between stem- and foliated-dendrite growth (Fig. 11-h). In this and earlier research we found evidence of foliated dendrite growth for LG (Fig. 6), CG and chunky graphite (Fig. 8), and SG (Fig. 10-a,d).
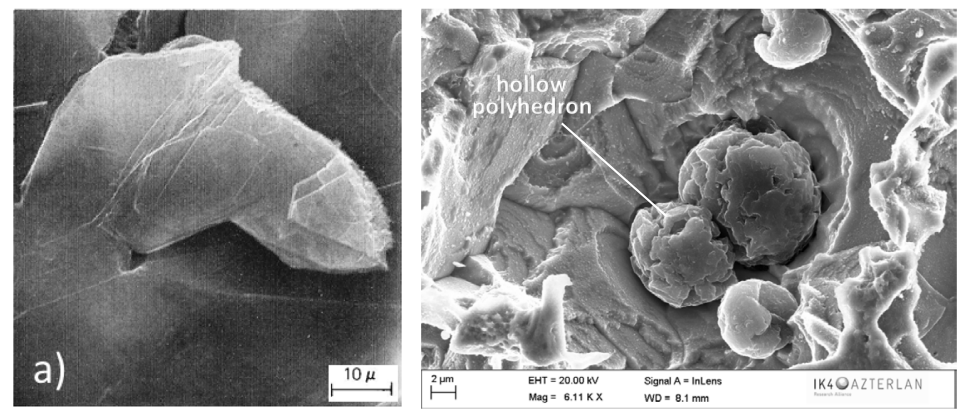

Fig. 12. SEM images supporting helical growth: a) in lamellar graphite [19]; b) hollow-polyhedrons in a graphite in a graphite spheroid from a room-temperature sample (compliments of A. Udroiu)

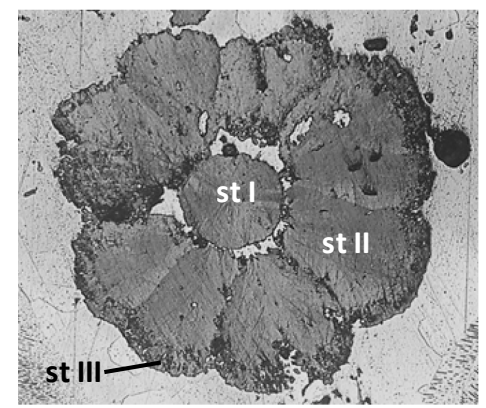

Fig. 13. Three-stage microstructure in a degenerated spheroid: I -curvedcircumferential growth; II -columnar growth; III - solid-state growth; (compliments of A. Udroiu)

The thermal/solutal instabilities at the graphite/melt interface complicate the physics, and may produce a three-stage SG microstructure, as shown in Fig. 13 for graphite floated in a large casting. Separated graphite columns indicate the beginning of formation of degenerate graphite. The mechanism for stage-I, solidification from the liquid, appears to be consistently explained by the curved-circumferential crystal growth mechanism. The fact that the graphite platelets are not in good contact with one another (Fig. 4-a) may be a consequence of foliated dendrite growth.

Stage-II solidification produces conical, layered sectors, similar to the pyramidal sectors found in ice and silicon crystals. Possible mechanisms include layer-growth through cone-helix, 2-D nucleation, or spiral dislocation, as well as helical growth. For the case of conical sectors growing in the liquid, as found for imperfect spheroids such as the one in Fig. 10-d and Fig. 13, the presence of tiled-roof configuration suggests foliated dendrite growth. As previously discussed [12], at sufficient Mg levels, the platelets aggregate in clusters that produce blocky graphite (Fig. 8-b), also found in natural graphite, and identified by Theuvissen et al. [31]

The diffusion of carbon because of decreased solubility in the austenite with lower temperature is the mechanism in stage-III. However, high diffusion rates may result in recrystallization of carbon and thus in the morphing of stage-III microstructure into the conical sector structure of stage-II. Examples of crystallization of amorphous carbon to form spheroids are found also for processes unrelated to metal casting, such as heating of amorphous carbon in an electronic beam [33].

Diffusion of carbon through solid austenite that occurs in stage III, and possibly partially in stage-II, followed by crystallization of the amorphous carbon, obscures the mechanism when 
graphite nodules are studied at room temperature. Thus, extending the results of the TEM analysis on this type of samples to explain crystallization from the liquid appears risky.

\section{Conclusions}

Extensive literature analysis coupled with interrupted solidification experiments confirmed that the basic building blocks of the graphite aggregates are hexagonal faceted graphite platelets generated through the growth of graphene layers. The platelets thicken through layer-growth from the edges of the platelet, through 2-D nucleation, or through spiral-dislocation growth. Graphite crystallization evolves through several mechanisms including, curved-circumferential, cone-helix (positive wedge disclination), helical (negative wedge disclination), and foliated crystal/dendrite growth. These mechanisms may operate separately or in combination to produce the variety of graphite morphologies observed in cast irons. Carbon recrystallization during solidification of graphite in the liquid and subsequent growth through the austenite shell and after solidification, greatly affects graphite morphology, and may obscure the solidification morphology on room temperature samples.

\section{References}

[1] A.K. Geim, K.S. Novoselov: Nat. Mater. Vol 6 (2007) 183-191.

[2] U. Nakaya, Snow Crystals: Natural and Artificial (Cambridge Univ. Press, Cambridge 1954).

[3] A. Hellawell: Prog. Mater. Sci. 15 (1970) 3-78.

[4] C.R. Loper, C.B. Kim, K.M. Htun, R.W. Heine: in Recent Research on Cast Iron, H.D. Merchant ed. (Gordon and Breach, New York, N.Y., 1968) 363-387.

[5] D.A. Granger, R. Elliott: in ASM Handbook Vol.15 Casting, D.M. Stefanescu ed. (ASM International, 1988) 159-168

[6] B. Lux, F. Mollard, I. Minkoff: in The Metallurgy of Cast Iron, B. Lux, I. Minkoff, F. Mollard eds. (Georgi Publishing Co., St Saphorin, Switzerland, 1974) 371-401.

[7] H Fredriksson, M Hillert, N Lange: J. Inst. Met. 101 (1973) 285-299.

[8] E. Tillová, M. Chalupová, L. Hurtalová: in: V. Kazmiruk ed., Scanning Electron Microscopy, (InTech, Chapters published March 09, 2012).

[9] D.D. Saratovkin: Dendritic Crystallization (Consultants Bureau, New York, NY, 1959)

[10] A.N. Roviglione, J.D. Hermida: Metall. Mater. Trans. Vol 35B (2004) 313.

[11]D.M. Stefanescu, G. Alonso, P. Larrañaga, E. De la Fuente, R. Suarez: Acta mater. 107 (2016) 102-126.

[12] D.M. Stefanescu, R. Huff, G. Alonso, P. Larrañaga, E. De la Fuente, R. Suarez: Metall. Mater. Trans. 47, (2016) 4012-4023

[13]D.H. St. John, L.M. Hogan: J. Crystal Growth 46 (1979) 387-398.

[14]V.N. Kvasnitsa, V.G. Yatsenko, J.A. Jaszczak: Can. Mineralogist 37 (1999) 951-960.

[15]D.D. Double, A. Hellawell: Acta Metall. 17 (1969) 1071-1083; 22 (1974) 481-487.

[16]D.D. Double, A. Hellawell: in: B. Lux, I. Minkoff, F. Mollard (Eds.), The Metallurgy of Cast Iron (Georgi Publishing Co., St Saphorin, Switzerland, 1975) 509-528.

[17] S. Amelinckx, W. Luyten, T. Krekels, et al.: J. Crystal Growth 121 (1992) 543-558.

[18] J.A. Jaszczaka, G.W. Robinson, S. Dimovskic, Y. Gogotsic: Carbon 41 (2003) 2085-2092.

[19] B. Lux, I. Minkoff, F. Mollard, E. Thury: in: B. Lux, I. Minkoff, F. Mollard (Eds.), The Metallurgy of Cast Iron (Georgi Publishing Co., St Saphorin, Switzerland, 1975) 495-508.

[20] S. Amini, R. Abbaschian: Carbon 51 (2013) 110-123.

[21] J.P. Sadocha, J.E. Gruzleski: in B. Lux, I. Minkoff, F. Mollard (Eds.), The Metallurgy of Cast Iron (Georgi Publishing Co., St Saphorin, Switzerland, 1975) 443-459

[22]K. He, H.R. Daniels, A. Brown, et al.: Acta Mater. 55 (2007) 2919-2927.

[23]D.D. Li, R.X. Tan, J.X. Gao, et al.: Carbon 111 (2017) 428-438.

[24]K.M. Fang, G.C. Wang, X. Wang, et al.: Science and Processing of Cast Iron VIII (Beijing, China, Tsinghua Univ. Press, 2006) 181-187. 
[25] T. Hara, T. Kitagawa, K. Kuroki, et al.: Material Trans. JIMM 55(9) (2014) 1500-1505. [26]I. Minkoff, I. Einbinder, Official Exchange Paper - Israel, Int. Foundry Congress (1963) 139143.

[27] M. Hamasumi, Trans. JIM, Vol 6 (1965) pp. 234-239.

[28]M.J. Lalich, J.R. Hitchings: AFS Trans. 84 (1976) 653-664.

[29] G.R. Purdy, M. Audier: in: H. Fredriksson and M. Hillert (Eds.), The Physical Metallurgy of Cast Iron, Stockholm (Mat. Res. Soc. Symposia Proc., North-Holland, NY, 1985), 13-23.

[30]B. Miao, D.O. Northwood, W. Bian, K. Fang, M. Fan: J Mater Sci 29 (1994) 255-261.

[31]K. Theuwissen, J. Lacaze, L. Laffont: Carbon 96 (2016) 1120-1128.

[32] P.C. Liu, C.R. Loper, T. Kimura, H.K. Park: AFS Trans. 88 (1980) 97-118

[33] D. Ugarte: Nature, London 359 (1992) 707-709. 